\title{
The Liminality of Loneliness: Negotiating Feminist Ethics and Intersectional Affectivity
}

\author{
Anastasia Christou ${ }^{1 *}$, Kate Bloor ${ }^{2}$
}

\author{
1 Middlesex University, UNITED KINGDOM \\ 2 Independent Scholar, UNITED KINGDOM
}

*Corresponding Author: A.Christou@mdx.ac.uk

Citation: Christou, A. and Bloor, K. (2021). The Liminality of Loneliness: Negotiating Feminist Ethics and Intersectional Affectivity, Journal of Cultural Analysis and Social Change, 6(1), 03. https://doi.org/10.20897/jcasc/11120

Published: July 31, 2021

\begin{abstract}
This paper draws on auto-ethnographic and creative material to disentangle loneliness as including moments of tension but also the potential for personal liberation. The analysis draws on intersectional reflexivity as a joint project building on feminist friendship and activist academic collaboration. Our collaborative critical auto-ethnography sought to reach the co-production of narratives of loneliness while embracing the diversities of our positionalities. Our differing points of departure and arrival were harnessed to understand our experiential perspectives on loneliness. We conceptualise through feminist and intersectional theories the liminalities of a 'biopolitics' of loneliness. We address ethical, affective and performative aspects of how loneliness is understood. We can then advance propositions for alternative analyses that can contribute to feminist studies of loneliness. In the analysis we clarify the often nebulous interconnections of materialisms, affectivities and ethical feminisms to disentangle loneliness from the 'individual experience' to a 'social platform' of wider collective responsibility in tackling some of its traumatic and destructive effects. We explore these issues in the emerging context of the unprecedented COVID-19 pandemic that has led to farreaching social, psychological, and physical impacts upon loneliness, in turn augmented by UK state policies.
\end{abstract}

Keywords: feminist ethics, liminality of loneliness, intersectional affectivity, critical auto-ethnography, performativity

\section{INTRODUCTION: THE PHENOMENOLOGY OF LONELINESS IN EVERYDAY LIFE}

Socialisation processes are positively enhanced when social subjects have a social surrounding that enables them to thrive (and not simply survive). When social isolation or loneliness abound, then feelings of vulnerability become heightened with an exacerbated need to reconnect with others (Courtin and Knapp, 2017; Hawkley and Cacioppo, 2010). Features of loneliness have an impact on physical and mental health as well as overall consequences for behavioural, cognitive and psychosocial development (such as premature mortality) (Leigh-Hunt, et al. 2017). The Jo Cox Loneliness Commission report (2017) called on the UK government to devise a national strategy to combat a condition that affects millions of people and is as harmful to health, according to medical experts as smoking almost a pack of cigarettes a day (Orr, G. June 2014) and is reaching 'epidemic' proportions (Psychology Today. n.d.)

Loneliness may (or may not) also be linked to gender (Victor et al. 2006), and a wide range of other (potentially interacting) socio-economic dimensions or life circumstances and experiences (Cacioppo and Cacioppo, 2018; Beutel et al. 2017; Courtin and Knapp, 2017; Hansen and Slagsvold, 2016; Cacioppo et al. 2010; Beal, 2006). 
Loneliness is not simply being alone (as different to social isolation) and any interventions to reduce loneliness and its impact on well-being require that the multi-dimensionality of social and behavioural effects, are taken into account (Courting and Knapp, 2017; Hawkley and Racioppo, 2010).

Public Health England conceptualise social isolation, loneliness and 'social inaction' (e.g. unable to participate) as overlapping (Varney, 2013: 6-10) . More specifically: Social isolation is an "absence of social interactions, social support structures and engagement with wider community activities or structures" (which can be linked to 'marginalisation' and 'discrimination'). Loneliness was seen as an 'individual's personal, subjective sense of lacking connection and contact with social interactions to the extent that they are wanted or needed" (ibid).

As such, both these two main concepts (whilst useful) tend to simplify or even avoid complex structural (and non-structural) causes of these social experiences. There is also less clear emphasis on the social and economic factors, processes, and specific barriers that continue to prevent engagement, for instance isolation could be created by 'marginalisation or discrimination by families or communities' but this is not explained or explored fully. 'Being alone' is something that may be forced upon many people not simply a lack of opportunity or engagement. Similarly, loneliness is seen as an individual and subjective experience, which is useful to some extent - since it potentially includes social, psychological, and physical needs, (e.g. the need to be physically cared for) whether or not people affected are 'aware' of that.

However from the point of view of intersectional and feminist thinking around loneliness (particularly at the current time) (e.g. Gao and Sai, 2020), we perhaps need to consider both macro and micro factors including both policy and structural drivers and the context, in relation to how individuals or groups and communities may (or may not) be able to utilise resilience against loneliness and why. We live complex lives with complex causes leading to these feelings and experiences. Loneliness is not just about being alone, and being alone is not the only factor in experiencing loneliness. We propose to reframe the concept of loneliness in the following way: Loneliness, is a social phenomenon experienced by individuals, groups and families within certain complex socio-economic circumstances, exacerbated by policies, belief systems (such as those which create racism or sexism), opportunities including income, life situations, all of which intermesh to reduce opportunities and wellbeing in those individuals and groups.

Some research identifies socially marginalised communities for example such as the elderly, or LGBTQIA+ groups and migrants, the chronically ill or caregivers etc., as potentially particularly prone to suffering from loneliness (Courtin and Knapp, 2017; Vasileiou et al. 2017; Hughes, 2016; Kvaal et al. 2014). All of these complex issues are highlighted in discussions related to dealing with the impact of COVID-19 and loneliness. Whilst there has been some attention paid to the impact of COVID-19 on different groups already experiencing social discrimination and marginalisation, the detrimental and multifaceted impact on certain groups may not necessarily be as well highlighted as others.

There are intense experiential, emotional and embodied modalities that shape the phenomenology of loneliness' (Dahlberg, 2007). In exploring new and emerging deep understandings of the spatial and temporal contexts of the liminality of loneliness, we are also compelled to question if loneliness might have a transformational potential within solitude. We seek to push these ideas into a rigorous dialogue with feminist theory and ethics to address questions of 'space' and 'self. This can usefully be based from critical auto-ethnographic research informed by sociocultural practices and the political geographies that shape the experiential dynamics of the liminality of loneliness. We address some of the core psychosocial underpinnings of loneliness that might become productive points of connection with the 'self and 'society'. We draw on auto-ethnographic accounts to address affective and embodied understandings of the phenomenology of loneliness in everyday life as spatially experiential liminality.

A feminist ethics paying attention to different identities and perspectives is centrally important to taking women's lives and experiences seriously, as well as being central to eliminating oppression of women, sexual minorities, and other oppressed groups. Thus, Jaggar (1992) framed 'feminist ethics' as the creation of a gendered ethics that aims to eliminate or at least ameliorate the oppression of any group of people, but most particularly women. We are reflective that while on the one hand our discursive choice of using the term 'feminisms' is one that aims to be inclusive (e.g. Karayianni and Christou, 2020) and on the other 'feminist' does not signify a holistic approach. At the same time we maintain awareness that feminism or feminist theory within the 'western' (white/colonial/mainstream/popular) academy resembles what Min-ha (1987) calls 'occupied territory', as space already marked by hierarchies and oppressions. Aligned with our continued activism, learning, research informedteaching and constant self-checks in our academic practice, we accept the limitations of the concepts we use, and by no means do we claim to have all the answers.

The social and political landscapes of loneliness we explore in this paper are inescapably marked by relations of power and ideology. These can take the form of gendered and classed divisions, along with the stigma (Tyler, 2020) attached, which often re-directs responsibility to the individual rather than society. When Van Gennep (1960) coined the term 'liminality', its explanatory purpose was to highlight the middling stages of ritual transitions. These liminal landscapes of loneliness can manifest across generational and age groups but are pronounced when coupled 
with other vulnerabilities (e.g. disability, disease etc.) and as a result develop into compounded layers of marginalisation and isolation. In this paper, we understand 'liminality' as 'performance ${ }^{1}$ ' of the 'flow of actions and interactions in generating new meanings and symbolic signifiers' (Turner, 1980). In this way, we uncover the subjectivities that shape loneliness experiences and trajectories, and, Turner's 'life crisis' rituals contribute to understanding how processes of socialisation may entail and exacerbate solitude. At the same time, the agency and subjective experiences of individuals develop within differing social frameworks and the meanings of such are generated through everyday life practices. The liminality of loneliness unfolds within temporal ${ }^{2}$ and spatial dimensions and can have elements of empowerment despite the isolation and lack of social interaction.

Loneliness often takes root in childhood and not solely as a transient state experienced and endured in a deep seated painful sense of emptiness during periods of adulthood (Sagan, 2017). Methods for managing the experience of loneliness over time may often direct attention to those suffering and highlight their resilience, such as efforts to connectivity and sociability. This can further stigmatise those suffering in underscoring an 'individual deficit' model rather than collective social responsibility. The phenomenology of loneliness thus should be attentive to the constituent elements that piece together the often puzzling accounts of the lived experience.

Loneliness is a commonly experienced phenomenon that characterises the human condition of existence as it might inevitably be experienced by most people, no matter if they are surrounded by others or on their own. Capturing its 'existential meaning without reducing its complexity' (Dahlberg, 2007:195) is challenging as there are multiple subjectivities that might saturate its meaning. Our auto-ethnographic research aims to partially fill this void by drawing on both the complexity of the phenomenon and the subjective elements that shape how it is experienced.

The experiential aspect of loneliness incorporates ethical and political dimensions too. And, within those parameters, a feminist ethical politics is a necessary project for change. For instance, (in opposition to Levinas, as argued by) Vikki Bell (2001:159) contends that:

"one can argue that it is in the way that the dangers of the non-ethical are handled that politics begins. If this is so, one can refigure the question of ethics within feminism. Ethics becomes a check on freedom and politics rather than its originary source".

By extension, (and, along with Michel Foucault and William Connolly as claimed again by), Bell (2001:159) argues:

"that ethical responses, while coming from the other, have also to be subjected to genealogical critique, so that their conditions of possibility are not naturalized".

Additionally, we see as central to further development, projects that acknowledge ethical feminist responsibility to alleviate the trauma of loneliness; which embraces those who require such a support, whilst creating a central priority, on the political issue(s) of, loneliness.

In the next section we outline our theoretical framework and core concepts while reflecting on methodological issues. We then briefly examine the developing impact of the COVID-19 pandemic, feminist perspectives and associated issues. We subsequently present our empirical auto-ethnographic and creative material grappling with wider ethical questions and advance propositions for a feminist approach to loneliness studies. We conclude by clarifying materialisms, affectivities and ethical feminisms ${ }^{3}$ to disentangle loneliness from the individual experience of tackling some of its traumatic and destructive effects, to a social platform of wider collective responsibility.

\footnotetext{
${ }^{1}$ From Goffman to Butler there are a number of detailed accounts of the usage of 'performance' and performativity which are elaborated in great detail by Ute Berns (2014) in 'The Living Handbook of Narratology'. Here we draw on performativity to refer to the level of the narrator's agency or act of narration in how we use auto-ethnography and poetry as our storytelling devices in this paper.

${ }^{2}$ Barbara Adam (1994) argues that the complex aspects of time should hold a central stage in social theory especially if individuals are to take responsibility for their actions: past, present, and particularly the long term future. An explicit understanding of time Adam contends, generates not only a basis for a more adequate social theory, but a chance to be a participating agent in a world where human creations have frequently become the factor controlling human life. We agree that to grasp the multiplicity of time is to come to terms with the complexity of our times, but see this temporal understanding on an equal conceptual footing with space, where social relations and social subjectivities unfold.

${ }^{3}$ The affective turn, new materialisms, and in particular the study of material-discursive and "affective processes in relation to a certain empirical study" (Knudsen and Stage, 2015: 1) focuses on affective encounters and embodiment as a crucial part of knowledge production; one that can formulate new questions, research agendas, and modes of data collection and analyses (ibid.). Affective methodology takes emotions and bodily affects such as love, disgust, suffering and desire seriously, because such resonances expose ethical dilemmas that are part of knowledge production processes, while simultaneously offering other modes of ethics.
} 


\section{THE LIMINALITY OF LONELINESS: THEORISING CONCEPTS AND CAPTURING METHODOLOGICAL INNOVATIONS}

In this section we situate our conceptualisation of loneliness within an intersectional and feminist theoretical context and reflect on our critical auto-ethnography (Harris and Watson-Vandiver, 2020). Loneliness is framed within ideologies, which function to conceal, mask and distort, the ethical citizenship relations in society (with its own collective responsibility). Leslie Armour (2014: 57) declares: “"Ethical citizenship' is a puzzle. An ethical citizen should be someone who accepts responsibilities and duties and acts accordingly. How is that possible amidst forces that are global and economies from which individuals and whole groups can be excluded? Good intentions and sound preparation may be of no avail. The identification of responsibility may be difficult. The ability to discharge it may not exist". What we explore in this paper is how this liminality of responsibility (and by extension, loneliness) can be addressed as a collective policy matter through feminisms that do not reduce action to solely an individual burden of change. The ideological parameters of loneliness reflect such partial truths, drawing attention to the suffering self as the 'consensual individual' to one's loneliness, and not to the role of (that and within) society. These (neoliberal) ideologies of loneliness, draw attention to fictional self-induced suffering, rather than a set of social circumstances created for those social selves. This is a conflictual stance and it brings a clear political dimension to the conceptual landscape of loneliness. Loneliness is not simply a condition; it is a structural matter replete with power.

We find conceptual clarity in employing feminist and intersectional theories to the study of the 'biopolitics' of loneliness. 'Biopolitics' is a complex concept and linked with Foucauldian social theory in exploring mechanisms and strategies whereupon social life processes are managed and controlled under regimes of authority through knowledge, power and subjectivities (Nilsson and Wallenstein, 2013). Although there is the original rendition of intersectionality in the field of feminist studies (Crenshaw, 1989; 1991) we embrace it as a theoretical and methodological tool to analyse power in its complex forms. This involves exploring the constraining social normativities that situate issues (structurally, discursively, institutionally, socially and culturally) and related social categorisations (gender, ethnicity, race, class, sexuality, age, generation, dis/ability as well as poverty, unemployment, mental health etc.) as producing (tautological) social constructions of inequalities and societal injustice. As an everyday life modality, "intersectionality also approaches lived identities, and systemic patterns of asymmetrical life opportunities and harms, from their interstices, from the nodal points where they hinge or touch" (May, 2015 :3).

Feminist and intersectional theories also perceive power and opportunities for resistance as processual and relational (Ahmed, 2017; Ferguson, 2017; Collins and Bildge, 2016; Butler, 2015; Abu-Lughod, 2013; Cho et al. 2013; Fraser, 2013; Hemmings, 2011), thus in anticipation of agency and in opposition to structural and ontological obstacles that might impede dissent. While we do not align our thinking with binaries of oppression/agency or the latter in terms of power/resistance solely, we see an intersectionally aware position to loneliness as one precursor for action collectively, as both personal and political empowerment with a transformative potential in eliminating loneliness. Hence, in our analysis here, loneliness is perceived as primarily an experience of unwarranted trauma and social suffering. However, other approaches can envisage the departure from oppression and aim to identify sites of resistance within loneliness - to view forms of societal organisation that would eliminate this trauma (preventatively) such as change brought about by wider collective action. To achieve this theoretically:

\footnotetext{
"As a critical heuristic, intersectionality offers many valuable tools and skills in this regard. For instance, in the interests of 'deciphering' power, it directs our attention to gaps, inconsistencies, opacities, and discontinuities and insists that such omissions or silences be treated as (potentially) meaningful and significant, not just as obstacles to work around or anomalies to set aside" (May, 2015: 227).
}

This journey to disentangle feminist loneliness studies is a pathway that entails moments of tension and liberation, enmeshed with intersectional reckoning and reflexive awakening. As a joint project building on feminist friendship and activist academic collaboration, it is also an enriching project of potentialities for personal growth and realisation. Our collaborative critical auto-ethnography sought to reach co-production of narratives of loneliness while embracing our diversities, positionalities and our differing experiences of loneliness and life more generally.

We decided to undertake a qualitative, interpretative, but not wholly un-structured approach to data gathering and analysis (i.e. not coding). This was with a view to building theories, from both our data (auto-ethnographic writing, observations and discussions) and existing knowledge (via our literature review exploring bodies of work and published academic and policy interventions). This left us with a measure of flexibility in which preconceptions were minimalised and outcomes undetermined but employing some degree of systematic reflection, as in, grounded theory with an intersectional feminist slant. 
In order to capture some of these methodological complexities and enable this process, we agreed to exchange written creative and intellectual reflections, of our personal experiences. This follows an approach identified (useful here and now) as collaborative auto-ethnography (Roy and Uekus, 2020) and increasingly used to explore pandemic experiences (Raimondi, 2021; Zheng, 2020). This exchange then led to deeper and more critical discussions around the literature, how it links to experience, and contextual issues. One author drew on, and utilised the genre of poetry, to express deep reflective thought, emotion and the complexity of the dimensions of experience, and the (sometimes affectively elusive) loneliness. The use of poetry in this paper is to capture, signify and illustrate these complexities where appropriate. This approach is now being increasingly used not only in multidisciplinary research (McCulliss, 2013; Prendergast, 2009) but also as a specifically feminist methodology (Faulkner, 2020; 2018) and therapeutic auto-ethnographic encounter (Sharma, 2020). These methods proved pivotal in exposing some important nuances and complex mappings, in a dynamic process, allowing the intermeshing of personal experience, sociological theory, an understanding of policy and practice around loneliness in the UK (and specifically COVID19) and the current political climate (e.g. history of austerity) .

Furthermore, we see this as an 'antidote' to the reductionist quantitative, policy-driven, approach to loneliness in academia. Complex experiential perspectives become reduced to socio-economic characteristics largely speaking disaggregated from each other. This inevitably misses crucial and important nuances, of the interactive and dynamic relationship between personal experience, and socio-economic structural conditions. Here, we agree with Fakoya et al. (2020) that the individuality of the experience of loneliness and isolation may cause difficulty in the delivery of standardised interventions. They correctly observe that there is no one-size-fits-all approach to addressing loneliness or social isolation, and hence the need to tailor interventions to suit the needs of individuals, specific groups or the degree of loneliness experienced. Therefore, future research should be aimed at discerning what intervention works for whom, in what particular context and how. It has been suggested that "making theory from the self requires a critical engagement with autoethnography" (Boon, et al. 2018:7) and in this sense the researchers are the central research instruments encompassing both an ontological and epistemological nexus to theorise from personal biographies which in turn will interrogate the social and reflect wider social practices and processes (Ellis and Bochner, 2016; Reed-Danahay 1997).

In our collaborative approach we piece together somewhat discordant edges of emotions and embodiments, memories and self-narrations. While not seeking harmonisation of subjectivities of our life/scapes ${ }^{4}$ we became aware of our deeply embodied social geographies of loneliness. All these aspects were woven into the analysis informed by our feminist and intersectional positionalities. We thus agree that, "in this collaborative venture, we operate from the premise of embodied autoethnography, concerned both with the embodied nature of political, social, and cultural relations (that is, how we are intersectionally shaped by our fleshy, material selves), and with the conceptual insights and knowledges that emanate from our lived experiences of our bodies" (Boon et al. 2018:7).

Finally, this leads to the concept of embodiment, a central focus in this paper and of feminist theory. It is the site for the social and symbolic construction of sexuality and sexual difference, a focus of subjectivities and performativities, a gazing field of materialities from commodification and objectification to caring, and, the location of a politics of exclusion (or inclusion) power, affect and resistance (Braidotti, 2011; Butler, 1999; Young, 1990).

Lived bodies and embodiment as social practice and sociological discourse are often messy and ambiguous in their interpretations. Interactions are not easily reducible to single meanings and this might embed ambiguity in how we situate and position bodies and embodied actions. Corporeal interactions also involve hierarchies of power and knowledge, hegemonic processes and differing locational positionalities (Shilling, 2003; Williams and Bendelow, 1998). For instance: "Studying people's experiences with chronic illness and disability teaches us of the fragility of our body and its appearance, and how subject we are and have always been to contingencies that affect it. Such realizations change the view we believe others hold of us and the actions we take in response to our imagined view - whether of awe and respect or of frailty or incompetence" (Charmaz and Rosenfeld, 2006: 36).

As a result of hierarchies of power and hegemonic exclusions, experiences of embodied social inequalities are contained in social relations. Yet, "embodied social inequality is therefore not the inevitable product of organic interaction, but instead the unfortunate by-product of the discursive and practical solidification of ideologies" (Vannini and Waskul, 2006:196.). We are thus living in 'somatic societies' (Turner, 1992) where bodies are sites that can be transgressed but also contexts where extensive socio-cultural and politico-policy issues are negotiated.

These kinds of negotiations are reflections of critical societal concerns that might become embodiments of disruptive social interventions. This is a way to think about political and protest interventions but also disruptions that yield contentious and controversial reactions: such as the washing up of dead migrant and refugee bodies on

\footnotetext{
${ }^{4}$ While the definition of 'lifescapes' suggests: “A layout or representation of one's life, often depicted by life experiences, events, and circumstances" (https://www.wordsense.eu/lifescape/), we use the backslash symbol (/) in order to signify that those representations of life experiences also include both 'escapes' and 'landscapes' in the experiential, emotive and imaginative sense.
}

C 2021 by Author/s 
the shores of wealthy nation-states reflecting social subjects seen as 'despicable others'(Christou, 2018). Such bodies trigger social panics and anxieties through possible contact zones which transfer fears of 'contamination'.

Scholars have noted a lack of consensus on a clearly defined intersectional methodology in public health, (particularly for quantitative studies), due to a disconnect between theory and the development of intersectional research designs and questions (Bowleg, 2012). So, finally, the engagement we pursue with intersectional theory (Cho et al. 2013) is one where intersectionality reflects the idea that individuals belong to multiple social categories (such as gender, ethnicity, social class, or disability) and these are intersecting while creating opportunities and constraints, where people depending on particular intersections and social context experience dis/advantage (Collins, 1990; Crenshaw, 1991). While an intersectional approach can make policies effective, it is claimed by definition 'the winning solution', but whether governments want to make such an investment is a political choice (Meier et al. 2015). By maintaining a focal point on how individual experiences are shaped by the socio-political embedded frames we discuss, loneliness becomes entrenched in human experience and not a web of policy imaginaries.

In the next section we explore the context of the new and challenging situation globally and nationally of the pandemic and its threats and impacts. We also explore responses from feminist thinkers, academics and related debates, including COVID-19 policy and practice and the role of gender specifically affecting women.

\section{FEMINISMS, COVID-19 AND LONELINESS}

The unprecedented circumstances experienced across the globe currently regarding the pandemic, resulted in an explosion of discussion, comment, and research into many different dimensions related to this public health and social crisis. Interestingly, some issues affecting gender (e.g. men dying more; mostly women experiencing domestic violence and bearing the burden of caring) have made it into the mainstream media (and perhaps public consciousness and beyond) (Armstrong, 2021; Chadwick, 2021; Blanchard, 2021; Express and Star, 2020). We see an extraordinary and probably unparalleled focus on the complexities of the social impact of this situation in the public and academic domain. However there are debates about how women's voices and perspectives have not been emphasized as much as men's (Majid, 2020).

We examine the current (general) understanding within feminist thinking, of issues related to the COVID-19 crisis. Equally important background is the relationship between COVID-19 and the social changes and its impact on loneliness. Instances and experiences of loneliness have become more ubiquitous to some degree (affecting all areas of social life and all people); unusual (i.e. different types of new social experiences such as the lack of social contact through work) and demonstrating more unequal effects (distinct pandemic policies / services impacts, and health and social inequalities).

Whilst there is growing focus on COVID-19 and loneliness in both academic and mainstream media outlets, there are overly simplistic policy-orientated perspectives regarding the interaction with social isolation and different life and social circumstances. There is little mention of any of the distinct socio-economic interactions (e.g. between gender, race, social status, economic status) in terms of experiences of the illness/risk, and/or health services access and provision, or social/care needs of different groups, or of the policy responses to any of that (e.g. Sanders, 2020).

Within more explicitly feminist orientated discussions, a number of perspectives and interacting issues have been identified nationally and globally (Nanthini and Nair, 2020; Berkhout, and Richardson, 2020; Ozkazanc-Pan and Pullen, 2020; Ashoff (n.d)). Clearly the impact of COVID-19 on communities of people (and specifically women) is complex and many forms of discrimination, exclusion, disadvantage, have been exacerbated by it, and the policies, introduced to deal with it (Feminist response to COVID-19 (n.d); Ashcroft (n.d); Brooks, 2020; BBC World Service, 2020; Al-Ali, 2020; Rigby, 2020; Gbowee, (n.d)).

Of course internationalist perspectives add in global South perspectives that critique white feminist dialogue and western interests "paying attention to the intersectional pre-existing inequalities that have given rise to specific risks and vulnerabilities" (Al-Ali, 2020: 1). These more inclusive and global perspectives draw attention to the multiple and intersectional dimensions adversely affecting women (and specific groups including those affected by poverty) during the pandemic resulting in an 'exacerbation of gender (in) equality'. Further they advocate paying attention to comprehensive holistic solutions that embrace 'feminist economic visions' in a planned economic recovery plan. This requires a prioritisation of care and social reproduction taking into consideration unpaid and undervalued labour, increasing state support and critical investment in key services, securing pay and work conditions for frontline workers so their rights and job security are improved with better social and safety nets. We note that whilst there are emerging and explicitly feminist policies and governmental approaches, such as that from Hawaii (Hawai'i State Commission on the Status of Women Department of Human Services, April 2020), these approaches may remain few and far between. Given the complexity of the relationship between women's social lives, gender roles, caring responsibilities, types of work and other social inequalities of many different kinds, 
set against access to services and opportunities, post COVID-19 policies must address these, with a coherent set of strategies.

In the next section we delve into our empirical data to discuss liminal aspects of loneliness and how we negotiate or navigate interaction and solitude. Loneliness in this sense is an amplified constellation of feelings of estrangement leading to social separation and eroding social emplacement. It is thus perceived as a 'feeling state' and an 'emotion cluster' (Bound Alberti, 2018) which points to its complexity, messiness and ambiguity.

\section{AUTO-ETHNOGRAPHIC ENCOUNTERS: PERFORMATIVITIES OF SOLITUDE AND AFFECTIVITIES OF LONELINESS}

In our research on loneliness we adopt an auto-ethnographic approach that delves into the interconnectedness of researcher reflexivity, subjectivities and social experience. Grammars of individuality intersect with vocabularies of solitude when articulating experiences of loneliness while also embedding those stories in family, kinship and social relations. Throughout the discussion it becomes clear that intersectionalities of gender, ethnicity, class, dis/ability, sexuality, age and generation are means of anchorage and dis/connection in a wider societal abyss that does not always engender a sense of ontological security in the loneliness of the self.

For one, loneliness in the auto-ethnographic accounts appears to be either an aspect of a 'temporality of struggle' or a time-dependent phenomenology. In either case, the temporal dimension is very important. For instance, generation, age, life stage, the time before, during or after an illness or personal tragedy, etc. are all integral to the how loneliness is both experienced/encountered and the impacts of such instances. We approach this experiential experience in auto-ethnographic observation and analysis, from the position(s) of identifying as disabled/ non-heterosexual and older woman, semi-retired and not living on a low income (second author) and additionally as one who self-identifies as a working-class academic activist, trade unionist, feminist and anti-racist migrant woman (first author).

We attempt to draw connections between our distinct complex lived identities and experiences in socioeconomic situation with the particular reflections from auto-ethnographic material for analytical and theoretical purposes. We also understand that our personal situations give us partial and incomplete perspectives on social experiences we have not encountered, and thereby draw on intersectional thinking to fill these potential gaps where possible.

Here are some reflections on how loneliness is interconnected with structural conditions, the state and the 'struggling' self from the perspective of being a disabled, Buddhist, non-heterosexual and older woman (second author):

I've come to reflect a bit more on the impact of chronic illness on the experiences of socialising and loneliness. .... also experienced yet another barrier to receiving support through the state (waiting nine months for psychological help)

.... and in addition to that being LGBT, there are particular ways in which I can't socialise ... I can't possibly participate in an equal and easy way.

The problem here is that actually you can get used to it; can get used to being 'pushed out of society' and the isolation that results from that - and then sometimes you can't even see it yourself.

There's also how chronic illness can affect self-esteem; self-esteem can affect the way people relate socially, and how this can impact then on the usual socialising and emotional needs the people bave. It is difficult to socialise when your own selfesteem, albeit mosth in general terms $O K$, underneath that can be a continuous and almost 'central fear' of being rejected, in fear of 'not being up to perform' like other people, as a physically challenged/ differently abled person. (pre-pandemic extract)

In the extract above, the intersectionalitiess of dis/ability, sexuality, age and other parameters of individual identities are stretched to the extreme when one has to develop coping mechanisms and self-esteem survival strategies in the presence of an absent state and governmental system of support.

The more 'beaten down' one is from one's illness, the barder it is to get out and integrate and mix with people - and the more loneliness becomes another additional problem on top of illness. (pre-pandemic extract)

Self-esteem, self-identity, personal resilience and autonomy are further 'crushed' when individuals make extensive efforts not to 'burden' family, friends and loved ones. 
......scared of getting too close to people in case I 'let them down' because I can't sustain a relationship. My friendships are strong and they are loyal but I'm very mindful not to 'burden them too much' with my own emotions so as not to complicate the relationship. (pre-pandemic extract)

This puts the onerous responsibility onto the individual, already stripped of layers of dignity - under pressure to reach 'superhuman' endurance (as indicated in the narrative of Paralympic athletes below as role models). And, while, the extraordinary achievements of Paralympic athletes should be applauded, recognised and celebrated, it is the 'celebrity' status endurance that often is conferred to all physically challenged/differently abled groups that requires caution in moving away from essentialisations of capacities. It is exactly such performativities expected from all physically challenged/differently abled groups and the enhanced affectivities that such expectations can have on people which can exert further loneliness.

Images of courageous and triumphant sporting heroes who are physically challenged/ differently abled, momentarily motivate me, but underneath that there is a sinking feeling of unattainable achievements being dangled in front of my nose - in order to make me feel even worse about myself and my situation. ... My own self-esteem and self-identity is damaged and crushed by my illness... (pre-pandemic extract)

Loss of identity or threat to identity is another emerging theme in the experiences of loneliness especially with social changes related to the pandemic. People working from home, combining childcare with work, carers having to move in with parents, and the general changes around socialising and mixing, bring profound changes and loss of various kinds. These losses can be linked to various dimensions of our identities, which can be multiple and experienced differently by different groups.

... in the pandemic I'm cut off from the lesbian and gay community that was 'always there for me', in pubs, in quizzes, in special events, in certain places, online and physically -opportunities to embrace and express and engage with my sexuality in a culture of affirmation and acceptance (during pandemic extract)

As such this raises the issues around the pandemic creating a new form of loneliness related perhaps to collective experiences of grief and loss, as illustrated by the first named author who self-identifies as a workingclass academic activist, trade unionist, feminist and anti-racist migrant woman.

5Poem: Discomfort as Grief: Poem \#2' (extracts below written during the 2020 pandemic)

I have captured the light from a million candles in your eyes.

They will not grieve the symphony of clouds piercing the dark purple sky.

Nearing the peak of despair, let me be your sanctuary from the tide of times.

Lack of access to appropriate state support services during the pandemic (such as the rolling out of vaccination prevention programmes to some types of physically challenged/differently abled people but not others) exacerbates feelings of abandonment, sitting alongside other forms of separation and the lack of social support or contact. Often it is effectively the promise and a degree of certainty of intervention and healthcare that provides reassurance, but when deeply affected by lockdown resulting in difficult access pathways, this liminality has massive impacts on anxiety and mental/physical health especially for physically challenged/ differently abled people.

... the uncertainty of vaccination programmes and its impact, provides us with hope but also not being able to access that early as a physically challenged/differently abled person, due to narrow criteria for inclusion, is the cause of worry. My life is impacted; I can't travel anywhere, I can't see anyone, and my life is on hold. (during pandemic extract; second author)

Another example when one author is denied access to dental care worsening chronic illness (being physically challenged/differently abled did not bring about priority care), triggered additional distress:

...feelings of being overpowered and crushed were immense. I felt completely powerless.... All of these worries and anxieties impact on the way I feel about my daily life, I think affected my levels of anxiety, probably my mental and physical health... (during pandemic extract; second author)

${ }_{5}^{5}$ Poetry by the first named author is forthcoming, 2021, in the International Human Rights Arts Festival, https://www.ihraf.org/ 
At the same time the new times lead to 'new forms' of social engagement sometimes overriding difference: groups of people and communities respond to crisis as well as a time when we could engender, a time of transformation and change:

I find myself moved by the efforts of my neighbours to help me when I need it. This is irrespective of my sexuality and of course some social divisions/differences have been swept away ....In some respects certainly in my area, it has made people kinder. (during pandemic extract; second author)

'Solidarity in Solitude: Poem \#3', (extracts below written during the 2020 pandemic; author one)

Restless lockdown diaries in the quarantine of minds: decluttering the hate, social distancing the poverty and giving solidarity a home.

Communities of crisis and we will decimate the ruins to heal again.

'Glimpse of Void: Poem \#1' (extracts below written during the 2020 pandemic)

Curtains drawn and darkness falls, they promised the dawn will come again.

Silent Spring.

Entangled pandemics with the patriarchy we would dismantle.

But high expectations of people even within the family context can become vehicles of leading to further loneliness when coping is difficult:

I am intrigued, I am concerned, I am both resisting and experiencing throughout my life loneliness. Often it has been because it is either challenging to trust people, make deep and authentic mutual connections with them or simply because of lack. of reciprocity when relationships become superficial, fleeting, fading away, selfish.

I know deep to my core how loneliness feels at all stages of my life course so far. Quite draining and often a source of loneliness to know that you are the one, perbaps the only one in your family who is responsible for the lives of all others. Indeed a burden and not a privilege to show any other buman elements of limitations and weakness.

This has been most exhausting and actually depleting when loneliness has been most pronounced during major life events, turbulence, loss, grief, illness, change. While there have been exceptions and once and a while on a rare, but very special occasion, somebody who has cared and has picked up the phone, sent a card, sent an email, offered to help in some way, has made a difference, for the most part I have felt alone while dealing on my own with serious existential and logistical life matters. (pre-pandemic extract; author one)

In capturing or even de-centring loneliness from identity, the realisation is that the self is not always in a state of void and emptiness; on the contrary it can be that the 'saturated' self (Gergen, 1991) is one of profound loneliness. Loneliness in this sense becomes a condition, a state of mind in the journey to endurance of personal struggle and hardship. It can be challenging when there is no collective to support the journey. This would offer the antidote which can be in the form of supportive kindness, generosity of time, compassionate caring, and selfless giving of $\mathrm{im} /$ material contributions. It is otherwise, not the void or the emptiness of the self, but astonishingly quite often the stark elimination of the collective (one person or more) presence, even symbolically in the contribution of the sympathetic ear to signify co-presence. The latter illustrates that loneliness emerges as the lack of recourse to the collective and not necessarily an individualistic absence, along the lines that mirrors what Lykes and Kemmelmeier (2014) have found in their study in confirming that levels of loneliness are higher in collectivistic compared with individualistic societies, but societies differed in terms of their predictors of loneliness. In collectivistic societies, the absence of interactions with family was more interlinked to loneliness than in the case of individualistic societies. Moreover, in individualistic societies, the absence of interactions with friends and having some kind of confidant is more closely linked to loneliness than in the case of collectivistic societies. Their findings are consistent with the notion that autonomy and choice with regard to interaction partners have greater implications for well-being in individualistic societies whereas traditional social bonds are more potent in collectivistic societies.

Loneliness in a generational sense (in different ways) can be an 'anti-feminist' experience and frequently entails efforts to process the increased instances of 'othering'. 'Non-intersectional' behaviours, and lack of understanding around difference, can forge distance between people or groups (othering them), and further exacerbate feelings of social rejection and loneliness. Within the divisions and fragmentations of feminist ideologies and practices, 
generational loneliness is a characteristic divider further exacerbating distance and dialogic interactions. Issues of 'authenticity' of feminist praxis are also at stake and ground loneliness in elements of the politics of practising feminisms.

\section{DISCUSSION}

Examining the policy research evidence does suggest a correlation between age/generation and loneliness with a set of more 'hidden' issues when it comes to caring responsibilities or disability ${ }^{6}$ involved in the process (Courtin and Knapp, 2017; Vasileiou et al. 2017; Kvaal et al. 2014). Research on loneliness has been considered sociologically challenging as regards its focus on individual emotions, but, at the same time revealing in that the subjective experience is critical for understanding a number of issues beyond the structural (Parigi and Henson, 2014). In the extracts above, the irony illuminated is that loneliness is not only a feminist issue; it can be an issue with feminists. That is, rather than collectively creating feminist spaces within intersectional practices where relationships can build on enhancing and fostering links to reduce loneliness, the 'clique' mentality can accentuate further marginalisation of those feminists who do not fit the 'clique' criteria model. Frequently, this translates politically into conceptualisations of (white) western feminism and the coloniality of power that has been referred to by Grosfoguel, Oso and Christou (2015) as enriching our understanding of intersectionality in the framework of modernity and the capitalist/imperial/patriarchal/racial colonial world-system which reproduces a northerncentric social science view of the world that comes from the experience of 'others' in the zone of being.

It might in a sense appear rather dated to think about the 'old feminist days' of 'consciousness raising', but those were encounters of authenticity exchange whereupon feelings of pain and exclusion (sexisms, racisms, ableisms, homophobias, ageisms, classisms) were shared and became learning experiences (Napikoski, 2019). However, these kinds of approaches need to be developed, and extended, given persistent and complex dimensions of oppression and emerging understandings of these, e.g. trans-issues. Of course issues of inequalities also persisted in the past, and even through a feminist lens tackling forms of discrimination, many voices were/are silenced e.g. the issue of transphobias (Lesbian, Gay and Bisexual Anti-Violence and Policing Group. n.d) or staff sexual misconduct in higher education (Massey, 2019). Loneliness thrives in places, times, situations, where discrimination or exclusion is rife. Programmes of inclusion of any kind therefore strike at the heart of the process of separation, barriers to understanding, and tackling core drivers of loneliness and ways of removing these barriers to understanding are crucial to removing loneliness.

Lewis and Hemmings (2019) explore the 'thick, suffocating fog of whiteness' in feminism in tackling creative possibilities of intersubjectivity. Creative possibilities of intersubjectivity can become means by which fragmentations in feminisms ${ }^{7}$ can become productive opportunities for dialogue and collaboration. Indeed, communication and collaboration would appear to be key in carving a pathway to tackling loneliness. It is the lack of open conversations and interactive collaboration that seem to impact on issues of self-esteem, isolation and depression. Being stuck in an idle space of feeling without agency can further exacerbate negative feelings. It is then experienced as 'perpetual grievance' in a "cycle of trauma produced by the toxicities of misogyny and racism and heteronormativity and class-based hatreds" (ibid). These experiences create silos that entrap us in these traumatic zones where 'othering' (Rohleder, 2014) is experienced by those who are denigrated, marginalised, and oppressed.

Eliminating the personal and social barriers to tackling loneliness should and can become a feminist project. This is a powerful realisation that if we do this in the context of feminist lives and ontologies and we could mould, and foster a type of feminism that is truly intersectional. These inclusive intersectional realisations and learning opportunities, can be created within social feminist activities and actions, to identify and overcome divisions by difference. This is a feminist strand as action to tackle loneliness. Loneliness is the ontological outcome of division when society is split, then distance creates uncaring. Intersectionality in the feminist approach we utilised does not suggest we all experience all social categorisations, in all occasions, of loneliness. As the extracts illustrated, for some people it might be disability coupled with sexuality and for others gender, ethnicity, generation, age, class. Taking an intersectional understanding of 'similar and different', highlights the interactive nature of these dimensions on loneliness, and refocuses us on what it means to be a feminist within that.

We also draw attention to the dimensions of time on multiple different levels in how we understand the experiential liminalities of loneliness. In the auto-ethnographic material we draw upon dimensions illustrating temporalities of 'personal time'. These unfold in such instances as how loneliness is linked as a 'time limited'

\footnotetext{
${ }^{6}$ For a detailed review of the field of affect and critical disability studies refer to Goodley, et al. 2019; 2018.

${ }^{7}$ On the fragmentations in feminism and with particular reference to sociology and social theory in the UK, see for instance: Platt, J., and Hopper, S. (1997). Fragmentation, Social Theory, and Feminism: Sociology in the United Kingdom. Contemporary Sociology, 26(3), 283-285. doi:10.2307/2654004
}

$10 / 18$

(C) 2021 by Author/s 
experience. So for example, institutional time (e.g. increasing demands of employers, work demands, where work is, types of work, travel time); state time/context such as demands/limitations that the state imposes on individuals, and the impact of public policy on the social sphere (such as benefits processes, waiting times and health and disability, lack of care /access to services) and collective time (e.g. unpaid carers, personal responsibilities and lack of choice). These temporal figurations become hidden modalities of loneliness in the absence or demands of time as well as how the socio-economic environment affects and shapes the impact of time (cf. Adam, 2002). Moreover, it would be particularly useful to know how these time dimensions figure in the more classic approaches to studying loneliness. We also observed that the other temporal aspects to loneliness and/or social isolation can change, as personal experiences and opportunities or lack of them change, and, therefore, it is not a single fixed experience (in time or space). It may have a tendency to be of a temporary nature within certain social and economic situations and contexts at micro and macro levels.

Thus, epistemologically, we see the storytelling of loneliness as a necessary narrative in understanding how more ethical feminisms can combat the phenomenon itself. Storytelling in the sense of auto-ethnographies can become a more rigorous tool, in that multiple intersubjectivities can illuminate how loneliness is a complex situated experiential encounter. In examining the more interpretive underpinnings of stories of loneliness we can identify failures of systems and policies by exposing the harm that destructive practices can have. By focussing on the way that individual experiences are conditioned by (and negotiated over) socio-political embedded frames, loneliness is entrenched in human experience and not a web of policy imaginaries.

\section{CONCLUSION: LONELINESS MATTERS - ETHICAL FEMINISMS, MATERIALITIES AND EMOTIONALITIES}

Feminist perspectives on loneliness pose ethical questions and require public policy answers. We draw from auto-ethnographic extracts through which we consider the meanings, implications and feminist possibilities of loneliness. To provide some degree of contextualisation of these personal experiences and reflections, we also take a critical look at the current government's strategic approach to tackling loneliness and its political and emotional development.

There are some positive aspects and dimensions to this strategy (HM Government, 2018) which does perceive loneliness as a serious social issue, given that it was led by a Labour MP, Jo Cox, who sadly lost her life. As a cross party initiative it shows loneliness needs to be tackled with a collaborative, partnership-led, collectively focused, but also an all-encompassing approach (using as many resources as possible within society). A considerable degree of funding has been channelled by the government towards these issues, and each government department was tasked with addressing loneliness within their work. Whilst it is clear that there is a focus on further 'civil connectedness' in various dimensions, through a variety of positive initiatives, at the same time (paradoxically perhaps) such governmental initiatives have a tendency to reify and essentialise the experience of loneliness, which is 'individualised' within the broader political context.

These issues of reification and essentialisation can be seen in the way in which loneliness is described and defined, as well as the way in which it is then decontextualised. This, (whilst also both appropriate and useful) also lends to an idea that personal resilience to circumstances is more relevant, than the effect of those social and economic circumstances, on individuals and groups (in the first place). Whilst the report suggests that 'loneliness can happen to anyone', research in this area demonstrates that to a great extent, clearly certain groups of people are more likely to suffer it, to much greater degree as well, including those most affected by cuts in public spending and austerity.

Characteristically the report states a definitional approach to loneliness as:

..."a subjective, unwelcome feeling of lack or loss of companionship. It happens when we have a mismatch between the quantity and quality of social relationships that we have, and those that we want" (HM Government, 2018:18).

This 'way of thinking' about loneliness as a 'single concept' in such a unidirectional and mono-dimensional perspective (as compared to a critical feminist and intersectional perspective) and experienced by an individual or 'groups of individuals' disconnects that experience from the broader socio-political and economic context. This lends to the idea that 'only individuals', can take responsibility for loneliness by identifying 'expectations' as being why people feel disconnected, that is, it leads to the idea that behavioural interventions are more relevant. This shifts away from the idea that interventions that improve the overall quality of life in more material ways might have an impact on loneliness (ironically perhaps a perspective that many participants in the report, might agree with). 
To illustrate this (though there are many examples) there are sections dealing with physically challenged/differently abled people specifically (as if somehow their experiences are divorced from those of women, carers, unemployed people etc.). Clearly, people who are physically challenged/ differently abled struggle to maintain social contact as well as form relationships and maintain those in positive ways that are meaningful to them and provide a degree of support. The socio-political context that affects other groups of people will also 'cascade into' the experience of physically challenged/differently abled people, to the framing that physically challenged/differently abled people do not live in isolation from others, even if lonely.

This government report, rather than exploring the difficulties of physically challenged/differently abled people in the context of their overall policy impact including a shrinking public sector, and the impact of austerity on them, instead focuses on the potential impact of physically challenged/ differently abled people 'returning to or being able to work' as a key solution. The real physical organisational barriers to and the reality of 'returning to work' as a physically challenged/differently abled person, makes this kind of approach alarming.

The book 'Crippled: Austerity and the Demonization of Disabled People' (Ryan, 2019), demonstrates how physically challenged/differently abled people have been affected by austerity which impacts on their quality of life, opportunities and experiences. Their health in this context predictably likely to become poorer, their ability to connect less, so loneliness would be one outcome, from this process of disempowerment and undermining of basic human needs and rights. No amount of 'connecting existing resources organisations / networks' or 'pump priming' these connecting resources (important though they are) can make up for the overwhelming and profound impact of for instance withdrawing physically challenged/differently abled benefits on the grounds that this is 'fairer'.

So austerity and neoliberalism are impacting bugely on the most vulnerable people, forcing them back into the home and back into a more dependent and neglected state and place (auto-ethnographic reflection(s) on personal experiences; both authors).

We may need to embrace a set of social policies which are based on understanding that loneliness is 'experienced by individuals and groups', in ways that are due to societal discrimination and disadvantage. This needs also to acknowledge loneliness is experienced by those people and groups by virtue of a complex range of social and economic, physical and other circumstances. Loneliness if created by a combination of social changes, access to resources of various different kinds, political strategies and agendas that further disadvantage existing disadvantaged groups, and policies that hit the poorest and the most at risk of loneliness harder, requires taking centre stage in feminist intersectional agendas.

In a much broader societal context, the strategy whilst 'extending or refining existing projects and services, policy and practice', needs to be applied or implemented by tackling the inequalities (related to loneliness). These inequalities are embedded deeply in social systems and political action/inaction and have been clearly exacerbated in the current pandemic. We need a more strategic or holistic way to tackle loneliness and its impact, based on solid and changing understandings of how these inequalities develop and how the pandemic situation is affecting them. Intersectional thinking could be particularly useful since it enables loneliness to be seen as linked to complex and multidimensional social disadvantage(s) and the policies that create or aggravate these. We need more research and scholarly work to address these sorts of perspectives in more detail, drawing on existing and other academic work related to social processes of discrimination and disadvantage.

At the same time the ontological experience of feminisms could benefit from the intersectional understandings brought about by addressing loneliness, both as a set of political issues affecting many different disadvantaged groups, as well as the interactions between these factors, domains, dimensions and experiences. It is especially important to understand fully and completely the cumulative and multiple negative impacts inflicted on groups of people, who suffer multiple forms of deprivation, discrimination and disadvantage. These social situations arise from ideologies embedded in social systems and policies, and interacting multidimensional factors such as illhealth, risk of illness from COVID-19, related to poverty and low income, lack of educational and job opportunities, in a broader and changing social context. Some of these understandings and perspectives are already emerging within the COVID-19 context, either within (or outside of) an explicit feminist framework.

Perhaps all of these developing understandings contribute to advancing the alleviation of human suffering, wherever and however, it exists in relation to loneliness. The collective experience of this as societies almost certainly includes shared experiences of trauma, loss and grief, in many different forms in many different ways but experienced more deeply and more frequently, or in varying ways, by different groups of people.

As expressed in the poems by the first named author: 'Trilogy of Dystopian Contemporaneous Suffering Selfdom Illuminating Hope': 
'Glimpse of Void: Poem \#1' (extracts below written during the 2020 pandemic)

Contours of stark divides.

On pause, standstill in isolation....

The promise of hail cathartic, a glimpse of void.

They said summer will return and the hayy afternoons would silence the noise.

Obliterate the mood and the glimpse of void will prevail.

Nightmares have evaporated, there will be a new constellation of dreams.

Asymptomatic epoch of numbness, a glimpse of void, whispers in yellow fields.

We note that national and local organisations and government, businesses, charities, community groups have all tried to address isolation and lack of support in vulnerable individuals during this pandemic, including such initiatives as the Royal voluntary service support (The Royal Voluntary Service, 2020) accessed by any individual or by referral. However prior existing socio-economic inequalities have contributed hugely within certain areas and social groups, such that they were more likely to end up isolated or socially cut off, unsupported and suffering from loneliness. We need initiatives that speak directly to these economic and social inequalities.

Many feminist authors question the whole approach taken to the threat of COVID-19 in the UK and beyond, e.g. Branicki (2020) calls for a radical alternative to the normative assumptions of rationalist crisis management used to tackle the impact of COVID-19. A core question remains whether this is the time to formulate a better understanding (with feminist thinking) of discrimination and its causes, and how this can be a useful set of underpinning principles and efforts to tackle ongoing (and reproduced) health and life opportunity inequalities during this world crisis.

Feminists need to also benefit from tackling loneliness through their feminisms, in order to better understand the experience of other people within their sphere of political action, work, emotional spaces, socials lives and other intersectional domains. This may require feminism(s) to both reflect on, and understand loneliness 'better', and incorporate this within their work, networks, and action. For us, this might be an ongoing, but enormously necessary, activist project that deserves replication and expansion. We see this as a necessary component of a more ethical feminism. This may require feminists and feminist projects enabling both difference and similarities, across people who are considered, and shared, as a shared movement towards a more connected society. This can aim to move beyond a 'hierarchy of credibility' that can be prohibitive to embrace multiple interacting forms of discrimination which also change. This is illustrated by our auto-ethnographic work that shows both the different and shared experiences of loneliness across two very different lives and social situations.

We need reminding, of the famous quote from (the sadly missed) Jo Cox:

"While we celebrate our diversity, what surprises me time and time again as I travel round the constituency is that we are far more united and have far more in common with each other than things that divide us". (Demianyk, 2016, The Huffington Post)

\section{DECLARATION OF INTERESTS STATEMENT}

We state that we have no conflicts of interest to declare, and have not gained any financial or other benefits arising from direct applications of this work.

\section{ACKNOWLEDGEMENTS}

We gratefully acknowledge the abundance of collegiality offered by the journal Editor, Dr Simon Stewart, and, the three anonymous reviewers. The breadth, depth and scope of reviewer feedback has enriched the quality of our paper, while the declaration of one as a feminist scholar being moved by our work, has made us feel a little less lonely in navigating the battlespace of the neoliberal Academy, as survivors of the injuries that knowledge economy workers must endure. We, nevertheless, dedicate this paper to those few allies who make a stand for the rest of us, to enabling us someday, to indeed not just simply survive, but also to thrive. 


\section{REFERENCES}

Abu-Lughod L. (2013). Do Muslim Women Need Saving? Cambridge, MA: Harvard University Press. https://doi.org/10.4159/9780674726338

Adam B. (2002). The Gendered Time Politics of Globalization: Of Shadowlands and Elusive Justice. Feminist Review. 70(1):3-29. https:// doi.org/10.1057/palgrave.fr.9400001

Adam, B. E. (1994). Time and Social Theory. Cambridge: Polity Press.

Ahmed, S. (2017). Living a feminist life, Durham: Duke University Press. https:/ / doi.org/10.1515/9780822373377

Al-Ali, N. (2020). Covid-19 and feminism in the Global South: challenges, initiatives and dilemmas. European Journal of Women's Studies, 27(4), 333-347. https://doi.org/10.1177/1350506820943617

Armour L. (2014). Idealism and Ethical Citizenship, in T. Brooks (ed.), Ethical Citizenship. Palgrave Studies in Ethics and Public Policy. London: Palgrave Macmillan. https://doi.org/10.1057/9781137329967_4

Armstrong, C. (12 March 2021). The Telegragh. The gender pandemic gap: How COVID-19 sent women back to the 1950s. Available at https://www.telegraph.co.uk/women/life/gender-pandemic-gap-COVID-19-sentwomen-back-1950s/. (Accessed 5 March 2021).

Ashoff, N. (n.d). COVID-19 should be a wake-up call for feminists. Available at: https://jacobinmag.com/2020/ 04/covid-19-coronavirus-pandemic-feminism. (Accessed 2 June 2021).

BBC World Service, radio programme. (Mon 17 Aug 2020). The impact of the pandemic on gender inequality. Available at https://www.bbc.co.uk/programmes/w3csz7jp. (Accessed 13 February 2021).

Beal, C. (2006). Loneliness in older women: A review of the literature. Issues in Mental Health Nursing, 27(7), 795813. https://doi.org/10.1080/01612840600781196

Bell, V. (2001). On ethics and feminism Reflecting on Levinas' ethics of non-(in) difference. Feminist Theory, 2(2), 159-171. https://doi.org/10.1177/146470010100200203

Berkhout, S. G. and Richardson, L. (2020). Identity, politics, and the pandemic: Why is a disaster for feminism(s)? History and Philosophy of the Life Sciences, 42(4), 1-6. https://doi.org/10.1007/s40656-020-00346-7

Berns, U. (2014.) "Performativity", in P. Hühn et al. (eds.), The living handbook of narratology. Hamburg: Hamburg University. (Accessed 16 May 2021). http://www.lhn.unihamburg.de/article/performativity

Beutel, M. E., Klein, E. M., Brähler, E., Reiner, I., Jünger, C., Michal, M., Wiltink, J., Wild, P. S., Münzel, T., Lackner, K. J. and Tibubos, A. N. (2017). Loneliness in the general population: prevalence, determinants and relations to mental health. BMC Psychiatry, 17(1), 97. https://doi.org/10.1186/s12888-017-1262-x

Blanchard, S. (March 2021). Mailonline. Covid has killed 18\% MORE men than women in England and Wales but males are less likely to worry about the virus, data shows. Available at https:/ /www.dailymail.co.uk/news/article-9345995/COVID-19-killed-18-men-women-UK.html. (Accessed 5 March 2021)

Boon, S., Butler, L. and Jefferies, D. (2018). Autoethnography and Feminist Theory at the Water's Edge: Unsettled Islands. Palgrave MacMillan. https://doi.org/10.1007/978-3-319-90829-8

Bound Alberti, F. (2018). This "Modern Epidemic": Loneliness as an Emotion Cluster and a Neglected Subject in the History of Emotions. Emotion Review, 10(3), 242-254. https:// doi.org/10.1177/1754073918768876

Bowleg, L. (2012). The Problem with the Phrase Women and Minorities: intersectionality-an important theoretical framework for public health. American Journal of Public Health, 102(7), 1267-1273. https://doi.org/10.2105/ AJPH.2012.300750

Braidotti, R. (2011). Nomadic Subjects: Embodiment and Sexual Difference in Contemporary Feminist Theory. New York: Columbia University Press.

Branicki, L. J. (2020). COVID-19, ethics of care and feminist crisis management. Gender, Work \& Organization, 27(5), 872-883. https:// doi.org/10.1111/gwao.12491

Brooks, K. (Dec. 23, 2020). Opinion Feminism Has Failed Women. New York Times. Available at https:/ /www.nytimes.com/2020/12/23/opinion/coronavirus-women-feminism.html. (Accessed 13 February 2021).

Butler, J. (1999). Gender Trouble: Feminism and the Subversion of Identity. New York. Routledge.

Butler, J. (2015). Notes Toward a Performative Theory of Assembly. Cambridge, MA: Harvard University Press. https://doi.org/10.4159/9780674495548

Cacioppo, J. T. and Cacioppo, S. (2018). The growing problem of loneliness. The Lancet, 391(10119), 426. https:// doi.org/10.1016/S0140-6736(18)30142-9

Cacioppo, J. T., Hawkley, L. C. and Thisted, R. A. (2010). Perceived social isolation makes me sad: 5-year crosslagged analyses of loneliness and depressive symptomatology in the chicago health, aging, and social relations study. Psychology and Aging, 25(2), 453-463. https:// doi.org/10.1037/a0017216 
Chadwick, J. (10 March 2021). Mailonline. Women did nearly TWICE the amount of housework and childcare as men during the first COVID-19 lockdown, survey reveals. Available at https://www.dailymail.co.uk/ sciencetech/article-9346033/COVID-19-exacerbated-gender-inequities-housework-childcare.html. (Accessed 5 March 2021).

Charmaz, K. and Rosenfeld, D. (2006). Reflections of the Body, Images of Self: Visibility and Invisibility in Chronic Illness and Disability, in P. Vannini and D. D. Waskul, Body/embodiment: symbolic interaction and the sociology of the body (pp. 35-50). Aldershot: Ashgate.

Cho, S., Crenshaw, K. W. and McCall, L. (2013). Toward a field of intersectional studies: theory, applications, and praxis. Signs, 38(4), 785-810. https://doi.org/10.1086/669608

Christou, A. (2018). 'The Wretched of Europe': Greece and the Cultural Politics of Inequality. Humanity and Society, 42(1), 102-127. https:// doi.org/10.1177/0160597616664169

Collins, P. H. (1990). Black Feminist Thought: Knowledge, Consciousness, and the Politics of Empowerment. New York: Routledge.

Collins, P. H. and Bilge, S. (2016.) Intersectionality. Cambridge, UK: Polity.

Courtin, E. and Knapp, M. (2017). Social isolation, loneliness and health in old age: a scoping review. Health \& Social Care in the Community, 25(3), 799-812. https://doi.org/10.1111/hsc.12311

Crenshaw, K. (1989). Demarginalizing the Intersection of Race and Sex: A Black Feminist Critique of Antidiscrimination Doctrine, Feminist Theory and Antiracist Politics. University of Chicago Legal Forum, 140, 139167.

Crenshaw, K. (1991). Mapping the Margins - Intersectionality, Identity Politics, and Violence. Stanford Law Review, 43(6), 1241-1299. https://doi.org/10.2307/1229039

Dahlberg, K. (2007). The enigmatic phenomenon of loneliness. International Journal of Qualitative Studies on Health and Well-being, 2(4), 195-207. https:// doi.org/10.1080/17482620701626117

Demianyk, G. (17 June 2016). The Huffington Post. Jo Cox's Maiden Speech To Parliament: We Are Far More United Than The Things That Divide Us. Available at https://www.huffingtonpost.co.uk/entry/jo-coxmaiden-speech_uk_5762de5be4b03f24e3db840f (Accessed 15 February 2021).

Ellis, C. S. and Bochner, A. P. (2016). Evocative autoethnography: Writing lives and telling stories. New York: Routledge.

Express and Star. (Jul 15, 2020). Survey reveals gender inequality of COVID-19 lockdown. Available at https://www.expressandstar.com/news/uk-news/2020/07/15/survey-reveals-gender-inequality-of-COVID19-lockdown/. (Accessed 5 March 2021).

Fakoya, O. A., McCorry, N. K. and Donnelly, M. (2020). Loneliness and social isolation interventions for older adults: a scoping review of reviews. BMC Public Health, 20, 129. https://doi.org/10.1186/s12889-020-8251-6

Faulkner, S. (2018). Crank up the Feminism: Poetic Inquiry as Feminist Methodology. Humanities, 7(3), 85. https://doi.org/10.3390/h7030085

Faulkner, S. L. (2017). Poetry is Politics. International Review of Qualitative Research, 10(1), 89-96. https://doi.org/10.1525/irqr.2017.10.1.89

Feminist Response to COVID-19 (n.d.). https:/ /www.feministcovidresponse.com/. (Accessed 13 February 2021).

Ferguson, K. E. (2017). Feminist Theory Today. Annual Review of Political Science, 20(1), 269-286. https://doi.org/10.1146/annurev-polisci-052715-111648

Fraser, N. (2013). Fortunes of Feminism: From State-Managed Capitalism to Neoliberal Crisis. London: Verso.

Gao, G. and Sai, L. (2020). Towards a 'virtual' world: Social isolation and struggles during the COVID-19 pandemic as single women living alone. Gender Work \& Organization, 27, 754-762. https://doi.org/10.1111/gwao.12468

Gbowee, L. UNA-UK. (n.d) What comes next? Feminist principles for a post- future Available at https://una.org.uk/magazine/2020-1/what-comes-next-feminist-principles-post--future. (Accessed 13 February 2021).

Gergen, K. J. (1991). The saturated self: Dilemmas of identity in contemporary life. New York: Basic Books.

Goodley, D., Lawthom, R., Liddiard, K. and Runswick-Cole, K. (2019). Provocations for Critical Disability Studies. Disability \& Society, 34(6), 972-997. https://doi.org/10.1080/09687599.2019.1566889

Goodley, D., Liddiard, K. and Runswick-Cole, K. (2018). Feeling disability: theories of affect and critical disability studies. Disability \& Society, 33(2), 197-217. https:// doi.org/10.1080/09687599.2017.1402752

Grosfoguel, R., Oso, L. and Christou, A. (2015). 'Racism', intersectionality and migration studies: framing some theoretical reflections. Identities, 22(6), 635-652. https:// doi.org/10.1080/1070289X.2014.950974

Hansen, T. and Slagsvold, B. (2016). Late-Life Loneliness in 11 European Countries: Results from the Generations and Gender Survey. Social Indicators Research, 129(1), 445-464. https://doi.org/10.1007/s11205-015-1111-6

Harris, L. and Watson-Vandiver, M. J. (2020). Decolonizing Race and Gender Intersectionality in Education: A Collaborative Critical Autoethnography of Hope, Healing and Justice. Journal of Cultural Analysis and Social Change, 5(2), 09. https://doi.org/10.20897/jcasc/9321 
Hawai'i State Commission on the Status of Women (April 14, 2020). Building Bridges, Not Walking on Backs: Department of Human Services State of Hawai'i A Feminist Economic Recovery Plan for COVID-19'. Available at https://humanservices.hawaii.gov/wp-content/uploads/2020/04/4.13.20-Final-Cover-D2Feminist-Economic-Recovery-D1.pdeffbclid=IwAR1Twrc-SZPnZ0TPclM3gxVxO-

5AgagPb9IQIpoCdguyfH50_KyX6giqjoI

Hawkley, L. C. and Cacioppo, J. T. (2010). Loneliness Matters: A Theoretical and Empirical Review of Consequences and Mechanisms. Annals of Behavioral Medicine, 40(2), 218-227. https://doi.org/10.1007/s12160010-9210-8

Hemmings C. (2011). Why Stories Matter: The Political Grammar of Feminist Theory. Durham, NC: Duke University Press. https://doi.org/10.1215/9780822393702

HM Government, Department for Digital, Culture, Media and Sport (Oct 2018). A connected society a strategy for tackling loneliness - laying the foundations for change. Available at: https://www.gov.uk/government/ publications/a-connected-society-a-strategy-for-tackling-loneliness. (Accessed 15 February 2021).

Hughes, M. (2016). Loneliness and social support among lesbian, gay, bisexual, transgender and intersex people aged 50 and over. Ageing and Society, 36(9), 1961-1981. https:// doi.org/10.1017/S0144686X1500080X

Jaggar, A. M. (1992). Feminist Ethics, in L. Becker and C. Becker (eds), Encyclopedia of Ethics. New York: Garland Press.

Jo Cox Loneliness Commission report (2017). Combatting loneliness one conversation at a time A call to action. Available https://d3n8a8pro7vhmx.cloudfront.net/jcf/pages/164/attachments/original/1620919309/rb_dec17_jocox _commission_finalreport.pdf?1620919309. (Accessed 28 May 2021).

Karayianni, C. and Christou, A. (2020). Feminisms, Gender and Social Media: Public and Political Performativities Regarding Sexual Harassment in Cyprus. Feminist Encounters: A Journal of Critical Studies in Culture and Politics, 4(2), 34. https://doi.org/10.20897/femenc/8522

Knudsen, B. T. and Stage, C. (2015). Affective Methodologies: Developing Cultural Research Strategies for the Study of Affect. Basingstoke, Hampshire: Palgrave Macmillan. https://doi.org/10.1057/9781137483195

Kvaal, K., Halding, A. G. and Kvigne, K. (2014). Social provision and loneliness among older people suffering from chronic physical illness. A mixed-methods approach. Scandinavian Journal of Caring Sciences, 28(1), 104-111. https://doi.org/10.1111/scs.12041

Leigh-Hunt, N., Bagguley, D., Bash, K., Turner, V., Turnbull, S., Valtorta, N. and Caan, W. (2017). An overview of systematic reviews on the public health consequences of social isolation and loneliness. Public Health, 152, 157-171. https://doi.org/10.1016/j.puhe.2017.07.035

Lesbian, Gay and Bisexual Anti-Violence and Policing Group. (n.d) Transphobia. Available at: https:/ /www.galop.org.uk/transphobia/. (Accessed 6 May 2021).

Lewis, G. and Hemmings, C. (2019). 'Where might we go if we dare': moving beyond the 'thick, suffocating fog of whiteness' in feminism, Feminist Theory, 20(4), 405-421. https:// doi.org/10.1177/1464700119871220

Lykes, V. A. and Kemmelmeier, M. (2014). What Predicts Loneliness? Cultural Difference Between Individualistic and Collectivistic Societies in Europe. Journal of Cross-Cultural Psychology, 45(3), 468-490. https://doi.org/10.1177/0022022113509881

Majid, A. (30th October 2020). Pressgazette. COVID-19, women and the media: Study reveals exclusion of female voices in coverage of pandemic. Available at https://www.pressgazette.co.uk/womens-voices-underrepresented-COVID-19-media-coverage/. (Accessed 3 May 2021).

Massey, N. (4th May 2019). The Independent. UK universities spent $£ 87 \mathrm{~m}$ on 'gagging orders' to keep bullying and sexual misconduct claims quiet. Available at: https://www.independent.co.uk/news/education/educationnews/universities-uk-gagging-orders-scandal-sexual-misconduct-bullying-a8874401.html. (Accessed 6 May 2021).

May, V. (2015). Pursuing intersectionality, unsettling dominant imaginaries. New York: Routledge. https://doi.org/10.4324/9780203141991

McCulliss, D. (2013). Poetic inquiry and multidisciplinary qualitative research. Joumal of Poetry Therapy, 26(2), 83114. https://doi.org/10.1080/08893675.2013.794536

Meier, P., Mortelmans, D., Emery, L. and Defever, C. (2015). Intersecting Inequalities in the Life of Young Adults: A Reflection on Intersectional Policies, DiGeSt. Journal of Diversity and Gender Studies, 2(1-2), 57-74. https://doi.org/10.11116/jdivegendstud.2.1-2.0057

Minh-ha, T. (1987). Difference: 'A Special Third World Women Issue'. Feminist Review, (25), 5-22. https://doi.org/10.2307/1395032

Nanthini, S. and Nair, T. (2020). COVID-19 and the Impacts on Women. NTS Insight, no. IN20-05, July 2020. Available at: https://www.academia.edu/43746796/COVID_19_and_the_Impacts_on_Women. (Accessed 15 February 2021). 
Napikoski, L. (2019). ThoughtCo, Feminist Consciousness-Raising Groups: Collective Action Through Discussion. Available at: https://www.thoughtco.com/feminist-consciousness-raising-groups-3528954. (Accessed 6 May 2021).

Nilsson, J. and Wallenstein, S. O. (eds.) (2013). Foucault, biopolitics, and governmentality. Huddinge: Södertörn University.

Orr, G. (26 June 2014). The Independent. Britain has been voted the loneliness capital of Europe - so how did we become so isolated?. Available at: https://www.independent.co.uk/life-style/health-andfamilies/features/britain-has-been-voted-the-loneliness-capital-of-europe-so-how-did-we-become-soisolated-9566617.html. (Accessed 3 October 2019).

Ozkazanc-Pan, B. and Pullen, A. (2020). Reimagining value: A feminist commentary in the midst of the COVID19 pandemic. Gender, Work \& Organization, 28(1), 1-7. https://doi.org/10.1111/gwao.12591

Parigi, P. and Henson, W. (2014). Social Isolation in America. Annual Review of Sociology, 40, 153-171. https://doi.org/10.1146/annurev-soc-071312-145646

Platt, J. and Hopper, S. (1997). Fragmentation, Social Theory, and Feminism: Sociology in the United Kingdom. Contemporary Sociology, 26(3), 283-285. https://doi.org/10.2307/2654004

Prendergast, M. (2009). "Poem is What?" Poetic Inquiry in Qualitative Social Science Research. International Review of Qualitative Research, 1(4), 541-568. https://doi.org/10.1525/irqr.2009.1.4.541

Psychology Today. (n.d.). Loneliness. Available at: https://www.psychologytoday.com/gb/basics/loneliness. (Accessed 23 September 2019).

Raimondi, G. A. (2021). Between Applauses and Loneliness, Heroes/Warriors and Fear: Thoughts of a Medical Professor During the COVID-19 Pandemic. Qualitative Inquiry, 27(6), 738-739. https://doi.org/10.1177/1077800420941051

Reed-Danahay D. E. (ed.) (1997). Auto/ ethnography: Rewriting the Self and the Social. New York: Routledge.

Rigby, J. (30 July 2020). The Telegraph. The one place planning a 'feminist economic recovery' from. Available at https://www.telegraph.co.uk/global-health/women-and-girls/one-place-planning-feminist-economicrecovery-/. (Accessed 13 February 2021).

Rohleder P. (2014). Othering, in: T. Teo (ed), Encyclopedia of Critical Psychology. New York, NY: Springer. https://doi.org/10.1007/978-1-4614-5583-7_414

Roy, R., and Uekusa, S. (2020). Collaborative autoethnography: 'self-reflection' as a timely alternative research approach during the global pandemic. Qualitative Research Journal, 20(4), 383-392. https://doi.org/10.1108/QRJ-06-2020-0054

Ryan, F. (2019). Crippled: Austerity and the Demonization of Disabled People. Verso Books.

Sagan, O. (2017). The loneliness of personality disorder: a phenomenological study. Mental Health and Social Inclusion, 21(4), 213-221. https://doi.org/10.1108/MHSI-04-2017-0020

Sanders, R. (2020). 22 April ESSS Outline, social isolation and loneliness. https:/ / doi.org/10.31583/esss.20200422

Sharma, D. (2020). Writing poems: a waste of time or a savior of life-an autoethnographic exploration. Journal of Poetry Therapy, 33(3), 164-178. https://doi.org/10.1080/08893675.2020.1776967

Shilling, C. (2003). The Body and Social Theory. Sage.

The Royal Voluntary Service. (2020). Volunteers Needed Urgently This Winter to Support the NHS and Local Communities. Available at https://www.royalvoluntaryservice.org.uk/. (Accessed 15 February 2021).

Turner, B. S. (1992). Regulating Bodies. Essays in Medical Sociology. New York: Routledge.

Turner, V. (1980). Social Dramas and Stories about them. Critical Inquiry, 7(1), 141-168. https://doi.org/10.1086/448092

Tyler, I. (2020). Stigma: The Machinery of Inequality. London: Zed Books. https://doi.org/10.5040/9781350222809

Van Gennep, A. (1960). The Rites of Passage. University of Chicago Press. https://doi.org/10.7208/chicago/ 9780226027180.001 .0001

Vannini, P. and Waskul, D. (2006). Body Ekstasis: Socio-Semiotic Reflections on Surpassing the Dualism of BodyImage, in P. Vannini and D. Waskul (eds), Body/Embodiment Symbolic Interaction and the Sociology of the Body (pp. 183-200). Aldershot: Ashgate.

Varney J. (2013). Social Isolation. Presented at Public Health Approaches to Social Isolation and Loneliness: A Health and Wellbeing Directorate Seminar. Public Health England, London. Available at https://www.bristol.gov.uk/documents/20182/34732/Public-Health-Approaches-to-Social-Isolation-andLoneliness-Part-1_0.pdf/cb17ee30-0810-4587-bca6-1b589c597479. (Accessed 7 May 2021).

Vasileiou, K., Barnett, J., Barreto, M., Vines, J., Atkinson, M., Lawson, S. and Wilson, M. (2017). Experiences of Loneliness Associated with Being an Informal Caregiver: A Qualitative Investigation. Frontiers in Psychology, 8, 585. https://doi.org/10.3389/fpsyg.2017.00585 
Victor, C. R., Scambler, S. J., Marston, L., Bond, J. and Bowling, A. (2006). Older People's Experiences of Loneliness in the UK: Does Gender Matter? Social Policy and Society, 5(1), 27-38. https://doi.org/10.1017/s1474746405002733

Williams, S. and Bendelow, G. (1998). The Lived Body: Sociological Themes, Embodied Issues. Routledge. https://doi.org/10.4324/9780203260241

Young, I. M. (1990). Throwing like a Girl and Other Essays in Feminist Philosophy and Social Theory. Indiana University Press.

Zheng, S. (2020). Quarantine Life Is Stillness and Dialogue: A Reflective Autoethnography During a Global Pandemic. Qualitative Inquiry, September 2020. https:/ / doi.org/10.1177/1077800420960170 